\title{
The effects of dietary sugar-beet fibre and guar gum on lipid metabolism in Wistar rats
}

\author{
BY P. D. OVERTON, N. FURLONGER, J. M. BEETY, J. CHAKRABORTY, \\ J. A. TREDGER AND L. M. MORGAN* \\ Biomedical Research Division, School of Biological Sciences, University of Surrey, Guildford, \\ Surrey GU2 $5 X H$
}

(Received 6 April 1993 - Revised 3 December 1993 - Accepted 14 January 1994)

\begin{abstract}
This study investigates the mechanisms of action for the hypocholesterolaemic effects of sugar-beet fibre (SBF) and guar gum. Four groups of ten male Wistar rats were fed ad lib. on test diets containing either $100 \mathrm{~g} \mathrm{SBF}$ or guar $/ \mathrm{kg}$, or control diets containing $100 \mathrm{~g}$ cellulose or wheat bran $/ \mathrm{kg}$ for $28 \mathrm{~d}$. Food intake, weight gain and food consumption ratios were unaffected by the diets. Circulating cholesterol and hepatic cholesterol concentrations were significantly lower in both SBF- and guar-fed groups compared with either cellulose- or bran-fed animals. Circulating triacylglycerol concentrations were significantly lower in SBF- and guar-fed animals, but total hepatic lipid concentrations and hepatic and adipose tissue lipogenesis rates were unaffected by the diets. Hepatic cholesterol-7a-hydroxylase $(E C$ 1.14.13.17) activities were significantly higher in the guar-fed animals compared with cellulose or bran control groups. Hepatic 3-hydroxy-3-methylglutaryl-CoA reductase $(E C$ 1.1.1.88) activities were unaffected. Circulating bile acid concentrations were significantly lower in SBF- and guar-fed animals and faecal bile acid output was significantly higher in the guar-fed group compared with bran- or cellulose-fed groups. This study supports the hypothesis that guar exerts its hypocholesterolaemic effect via intraluminal bile acid binding and loss of cholesterol from increased faecal bile acid excretion. The mechanism of action for the hypocholesterolaemic effect of SBF is less clear; the results of the present study point to a mechanism involving disruption of the enterohepatic bile acid circulation, possibly via changes in the rate of absorption of dietary lipid.
\end{abstract}

Sugar-beet fibre: Guar: Cholesterol: Lipogenesis: Bile acids

Elevated serum cholesterol levels have been identified as a risk factor for coronary heart disease in man (Betteridge, 1989). It has been widely demonstrated that various kinds of soluble non-starch polysaccharide (NSP) can reduce circulating cholesterol levels. Two such preparations, guar gum, a soluble galactomannan, and sugar-beet fibre (SBF), which contains approximately $400 \mathrm{~g}$ soluble NSP $/ \mathrm{kg}$ in the form of pectic substances and soluble hemicelluloses, have well-documented hypocholesterolaemic effects on experimental animals and man (Jenkins et al. 1975; Hagander et al. 1988; Ide et al. 1991; Tredger et al. 1991). However, the mechanisms by which these fibres exert their hypocholesterolaemic effects are still not clear. Previous studies with guar have suggested a direct effect on intraluminal bile acid binding with consequent interruption of the enterohepatic bile acid circulation and loss of cholesterol from increased faecal bile acid excretion (Hansen $e t$ al. 1983; Kritchevsky et al. 1986; Morgan et al. 1993), a mechanism similar to that of cholestyramine (Tuomilehto et al. 1990). Interference with the intestinal uptake of lipid by guar, either as a result of bile acid sequestration (Gallaher \& Schneeman, 1986), or modulation of bulk phase diffusion because of the high viscosity of guar (Vahouny et al.

* For reprints. 
1980), has also been suggested as a possible mechanism. Other reports have suggested that volatile fatty acid fermentation products of NSP in the large bowel can modify the activity of regulatory enzymes involved in hepatic cholesterol synthesis (Chen et al. 1984). The specific mechanisms by which SBF lowers circulating cholesterol have been little investigated.

The present study investigates the mechanisms of action for the hypocholesterolaemic effects of SBF and guar in Wistar rats. Animals were given a diet using SBF or guar as the NSP source and compared with those where wheat bran or cellulose, insoluble NSP sources with no hypocholesterolaemic effect, provided the NSP. The enzymes 3-hydroxy-3methylglutaryl-CoA reductase (HMG-CoA reductase; $E C 1.1 .1 .88$ ) and cholesterol $7 \alpha-$ hydroxylase ( $E C$ 1.14.13.17), key regulatory enzymes in hepatic cholesterol metabolism, were measured. Circulating and hepatic lipid concentrations, circulating and faecal bile acid concentrations and rates of lipogenesis in hepatic and adipose tissue were also measured to monitor the effects of these NSP on bile acid sequestration and triacylglycerol metabolism.

\section{MATERIALS AND METHODS}

Animals and diets

Male Wistar rats (aged 12 weeks, body-weight $250-300 \mathrm{~g}$ ) obtained from the Rodent Breeding Unit, University of Surrey, were randomly divided into four groups of ten rats each. Two groups were given test diets containing either $100 \mathrm{~g}$ SBF (British Sugar Technical Centre, Norwich, Norfolk) or guar (Rybar Laboratories Ltd, Amersham, Bucks)/kg, and two groups were given control diets containing either $100 \mathrm{~g}$ wheat bran (Boots Co. plc, Nottingham, Notts.) or cellulose (Special Diet Services, Witham, Essex)/kg. The composition of the four diets is shown in Table 1. Before the experimental period all rats were fed on the control cellulose-based diet for 2 weeks to eliminate any effects of previous diet.

\section{Study protocol}

Animals were allocated to one of the four test diets for $28 \mathrm{~d}$. They were housed in groups of four to six. Fresh diet and water were provided without restriction. Food consumption per cage was measured daily, individual animal weights were recorded weekly and faeces were collected over a 24 -h period from each cage in the third week of dietary intervention. After $28 \mathrm{~d}$ serum and plasma samples were collected by cardiac puncture between 08.00-09.00 hours. Animals were immediately killed by cervical dislocation. The liver was excised and immediately processed for lipogenesis and enzyme studies. The remainder was snap-frozen in liquid $\mathrm{N}_{2}$ and stored at $-70^{\circ}$ for total cholesterol and triacylglycerol measurements.

\section{Serum measurements}

Total cholesterol, high-density-lipoprotein (HDL) cholesterol and triacylglycerol were determined by enzymic colourimetric methods using commercial kits purchased from Roche Diagnostic Systems Inc. (Welwyn Garden City, Herts.). Serum bile acids were determined using an enzymic-fluorimetric assay (Starkey \& Marks, 1982). Intra-assay coefficients of variation were $0.7,1.0$ and $2.4 \%$ respectively. All samples were analysed within a single batch.

\section{Faecal bile acid measurements}

The $24 \mathrm{~h}$ weighed rat faecal collections were mixed with three volumes of distilled water and allowed to soak for $30 \mathrm{~min}$. The samples were then frozen $\left(-70^{\circ}\right)$, lyophilized and reweighed. Portions of the lyophilized samples $(100 \mathrm{mg})$ were placed in borosilicate glass 
Table 1. Composition of the experimental diets

\begin{tabular}{lrrrr}
\hline \hline & \multicolumn{4}{c}{ Dietary supplementation } \\
\cline { 2 - 5 } & Cellulose & Bran & Guar & SBF \\
\hline Ingredient (g) & 310 & 310 & 310 & 310 \\
Maize starch & 310 & 310 & 310 & 310 \\
Sucrose & 198 & 198 & 198 & 198 \\
Casein & 80 & 80 & 80 & 80 \\
Maize oil & 50 & 50 & 50 & 50 \\
Vitamin-mineral mix & 2 & 2 & 2 & 2 \\
DL-Methionine & 105 & - & - & - \\
Cellulose & - & - & 105 & - \\
Guar gum & - & - & - & 105 \\
SBF & - & 105 & - & - \\
Wheat bran & &
\end{tabular}

SBF, sugar-beet fibre.

* 'Mazola', CPC (UK) Ltd, Surrey.

$\uparrow$ Commercial supplement (821105) obtained from Special Diet Services, Witham, Essex.

vials and washed three times with $3 \mathrm{ml} 2$-methylpropan-2-ol-water $(1: 1 \mathrm{v} / \mathrm{v})$. A $2 \mathrm{ml}$ volume of $0 \cdot 1 \mathrm{M}-\mathrm{NaOH}$ in ethanol $(900 \mathrm{ml} / 1)$ was added to each tube. The vials were capped and hydrolysed overnight at $90^{\circ}$ in an oven. A $300 \mu \mathrm{l}$ portion of the subsequent hydrolysate was removed and mixed with $2.7 \mathrm{ml}$ water before column purification. C18 Bond Elut columns ( $1 \mathrm{ml}$; Jones Chromatography, Hengoed, Mid Glamorgan) were prepared by washing with $3 \mathrm{ml}$ methanol followed by $3 \mathrm{ml}$ water. The diluted extract was then applied and eluted under vacuum. The column was washed with $3 \mathrm{ml}$ methanol $(150 \mathrm{ml} / \mathrm{l})$ under vacuum to ensure the columns were dry. The bile acids were eluted from the column with $3 \mathrm{ml}$ methanol. The methanolic extracts were then dried in a Gyro-Vap at $45^{\circ}$. The dried extracts were reconstituted in $50 \mu \mathrm{l}$ methanol then diluted out to $500 \mu \mathrm{l}$ in $50 \mathrm{mM}-\mathrm{Tris}-\mathrm{HCl}$, $\mathrm{pH} 9.5$. Total bile acids were measured in $50 \mu 1$ portions with an enzymic-fluorescence assay (Starkey \& Marks, 1982).

\section{Hepatic enzyme measurements}

Homogenates were prepared from 5 -g samples of liver. All preparative steps were performed at $4^{\circ}$. Liver homogenates $(250 \mathrm{~g} / \mathrm{l})$ were prepared in $01 \mathrm{M}$-potassium phosphate buffer, $\mathrm{pH} 7 \cdot 4$ containing 0.25 $\mathrm{M}$-sucrose, $2 \mathrm{~mm}$-dithiothreitol and $1 \mathrm{~mm}$-EDTA (Sigma, Poole, Dorset), using a Potter $\mathbf{S}$ homogenizer (Braun, Helsungen, Germany) for six strokes at $1200 \mathrm{rev} . / \mathrm{min}$. The resultant homogenates were centrifuged at $10000 \mathrm{~g}$ for $30 \mathrm{~min}$. The pellet was discarded and the resultant (S9) supernatants centrifuged at $100000 \mathrm{~g}$ for $1 \mathrm{~h}$. Portions of $\mathrm{S} 9$ were frozen at $-70^{\circ}$ for analysis. Cholesterol-7- $\alpha$-hydroxylase enzyme activities were measured in the liver $\mathrm{S} 9$ microsomal preparations according to the methods of Van Cantfort et al. (1975) with minor modifications. One $\mathrm{ml}$ of liver S9 preparation was incubated within a reaction mixture containing glucose-6-phosphate $(20 \mathrm{mM}), \mathrm{NADP}^{+}$ $(2 \mathrm{mM})$, glucose-6-phosphate dehydrogenase $(E C 1.1 .1 .49 ; 1$ unit), potassium phosphate buffer (100 mM, pH 7.4), $\beta$-mercaptoethanol (2 mM) and cholesterol (300 $\mu \mathrm{M})$ containing $9 \cdot 25 \mathrm{kBq}\left[{ }^{14} \mathrm{C}\right]$ cholesterol solubilized with $1.5 \mathrm{mg}$ Tween 80 . After 30 min incubation at $37^{\circ}$ the total lipids were extracted three times with $3 \mathrm{ml}$ petroleum ether, dried and separated by thin layer chromatography (Nimmannit \& Porter, 1980). Enzyme activities were expressed as pmol substrate converted $/ \mathrm{mg}$ protein per min. Total protein was determined 
by the method of Bradford (1976) using bovine serum albumin Fraction V (Sigma) as the standard. HMG-CoA reductase activity was measured in the $\mathrm{S} 9$ preparation by the method of Shapiro et al. (1974). The intra-assay variation was $6 \cdot 1 \%$ for cholesterol- $7 \alpha$-hydroxylase activity and $9 \cdot 3 \%$ for $\mathrm{HMG}-\mathrm{CoA}$ reductase activity.

\section{Hepatic lipid measurements}

Total hepatic cholesterol was determined in liver homogenates using the $o$-phthaldehyde method (Rudel \& Morris, 1973). Total lipids were extracted from the liver homogenates according to the method of Folch et al. (1956) and solvents were evaporated using a GyroVap (Uniscience, V. A. Howe \& Co., London). The lipids were reconstituted in $1 \mathrm{ml}$ chloroform and then subsequent $0.05 \mathrm{ml}$ portions were assessed for total lipids using the sulphosphovanillin reaction (Total lipids kit; Boehringer Mannheim GmbH Diagnostics, Mannheim, Germany). Intra-assay variation was $2 \cdot 6 \%$ for total hepatic cholesterol and $4.75 \%$ for total lipids.

\section{Hepatic and adipose tissue lipogenesis measurements}

Basal and insulin-stimulated adipose tissue fatty acid synthesis rates were measured in explants of epididymal fat pads prepared by the method of Dils \& Forsyth (1981), by determining the rate of incorporation of $\left[{ }^{14} \mathrm{C}\right]$ acetate (Oben et al. 1991). The intra-assay coefficient of variation was $8.5 \%$. Hepatic lipogenesis rates were measured in liver slices using $\left[{ }^{14} \mathrm{C}\right]$ glucose as the radiolabelled precursor according to the method of McGrath \& Rao (1977) with minor modifications in the lipid extraction (Bligh \& Dyer, 1959). The intra-assay coefficient of variation was $8 \cdot 4 \%$.

\section{Statistical analyses}

The data were initially checked for normality using the Kolmogorov-Smirnov goodness of fit test. One-way analysis of variance was then performed. The homogeneity of variances was checked using the Bartlet-Box $F$ test and Cochran's $C$ test and a $\log _{10}$ transformation was used where appropriate in order to satisfy the assumptions of analysis of variance. Specific group comparisons were made using Duncan's multiple range test. $P$ values of $<0.05$ were taken as statistically significant. Data analysis was carried out using the SPSS information analysis system (SPSS Inc. Chicago, IL, USA).

\section{RESULTS}

Food intakes and weight gains of the animals whilst consuming the test and control diets are shown in Table 2. There were no significant differences between groups in food intake, weight gain, or food consumption ratios during the experimental period. Food intake (measured as total food consumption/cage) was also similar between dietary groups, though it should be noted that the number of observations was small.

Circulating cholesterol and triacylglycerol levels following the different dietary regimes are shown in Fig. 1. Both guar- and SBF-fed groups had significantly lower plasma cholesterol and triacylglycerol levels compared with either the bran- or cellulose-fed groups. HDL-cholesterol levels were unaffected by the dietary treatments.

Hepatic cholesterol and total hepatic lipid concentrations are shown in Fig. 2. Liver weight was unaffected by dietary treatment. Hepatic cholesterol levels were significantly lower in the guar-fed group compared with all other dietary treatments $(P<0.05)$; hepatic 
Table 2. Weight gain and daily food intake of rats fed on diets supplemented with wheat bran, cellulose, guar or sugar-beet fibre $(100 \mathrm{~g} / \mathrm{kg})^{*}$

(Mean values with their standard errors for ten rats per dietary group)

\begin{tabular}{|c|c|c|c|c|c|}
\hline \multirow{2}{*}{$\begin{array}{l}\text { Dietary } \\
\text { supplementation }\end{array}$} & \multicolumn{2}{|c|}{ Initial wt (g) } & \multicolumn{2}{|c|}{ Wt gain (g) } & \multirow{2}{*}{$\begin{array}{l}\text { Mean daily food } \\
\text { intakef (g) } \\
\text { Mean of two } \\
\text { estimations }\end{array}$} \\
\hline & Mean & SEM & Mean & SEM & \\
\hline Cellulose & 299 & 6.5 & 180 & $11 \cdot 3$ & $39 \cdot 7$ \\
\hline Bran & 303 & $5 \cdot 6$ & 178 & $9 \cdot 1$ & $37 \cdot 4$ \\
\hline Guar & 298 & 6.6 & 170 & $8 \cdot 1$ & 37.9 \\
\hline Sugar-beet fibre & 300 & 6.8 & 174 & $11 \cdot 2$ & $40 \cdot 2$ \\
\hline
\end{tabular}

* For details of diets and procedures, see Table 1 and p. 386.

$\dagger$ Total intake per cage/no. animals per cage.

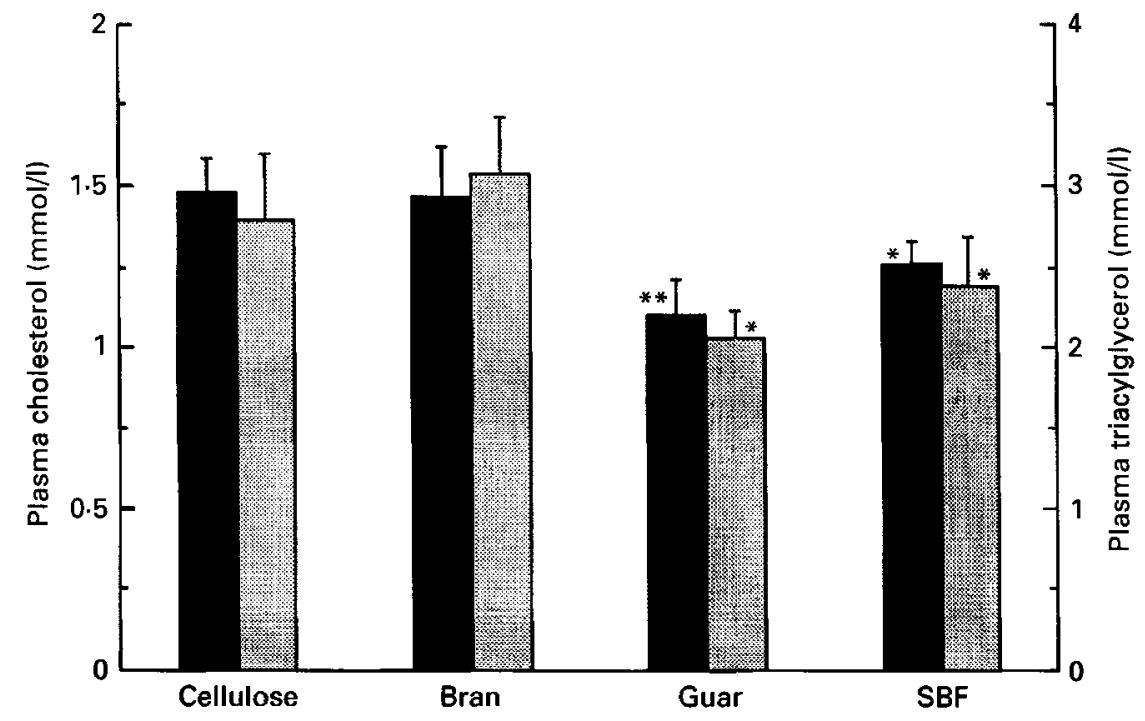

Fig. 1. Plasma cholesterol ( $\boldsymbol{\square})$ and triacylglycerol (图) concentrations $(\mathrm{mmol} / \mathrm{l})$ in rats fed for $28 \mathrm{~d}$ on diets containing cellulose, wheat bran, guar or sugar-beet fibre (SBF) $(100 \mathrm{~g} / \mathrm{kg})$. Values are means for ten rats with their standard errors indicated by vertical bars. Values significantly lower than either the cellulose or the bran control groups: ${ }^{*} P<0.05,{ }^{* *} P<0.001$.

cholesterol concentrations in the SBF-fed group were significantly lower than in the branor cellulose-fed groups $(P<0 \cdot 05)$. Total hepatic lipid concentrations were unaffected by the dietary treatments.

Hepatic and adipose tissue lipogenesis rates are shown in Table 3. There were no significant differences between groups in the in vitro incorporation of $\left[{ }^{14} \mathrm{C}\right]$ glucose into total lipids in liver slices, neither were there significant differences in the basal or insulinstimulated incorporation of $\left[{ }^{14} \mathrm{C}\right]$ acetate into fatty acids in epididymal adipose tissue.

Hepatic cholesterol-7 $\alpha$-hydroxylase and HMG-CoA reductase activities are shown in Fig. 3. Cholesterol-7 $\alpha$-hydroxylase activities were significantly higher in the guar-fed group compared with all other dietary treatments. Mean cholesterol- $7 \alpha$-hydroxylase activities 


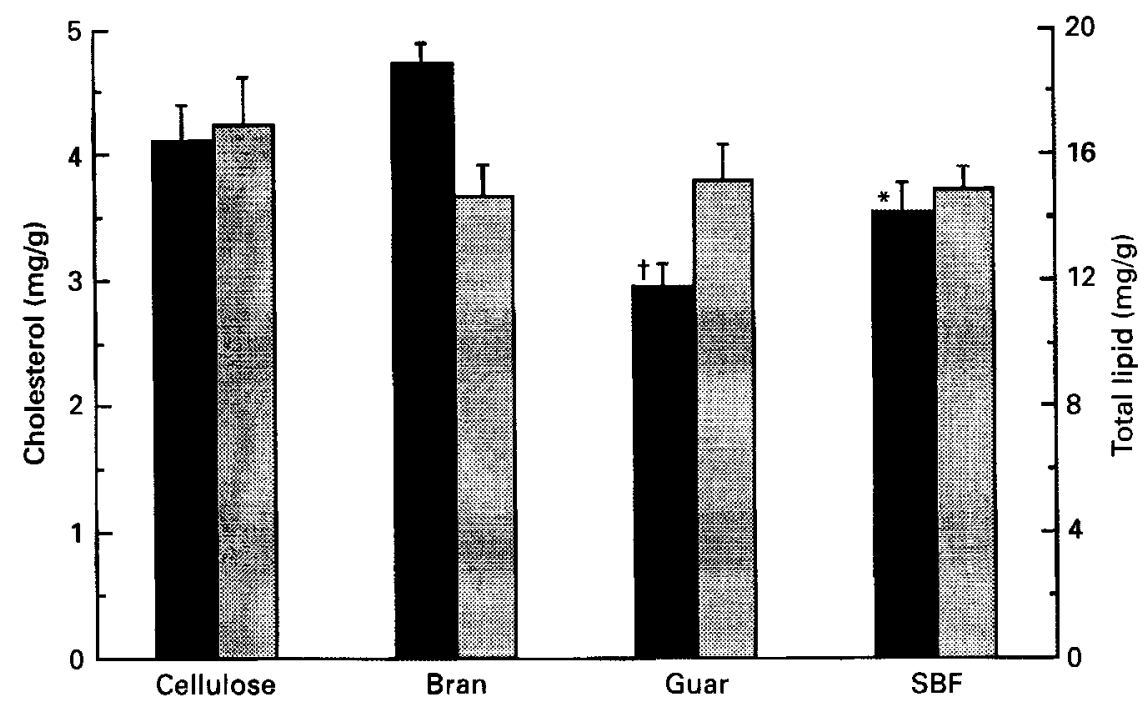

Fig. 2. Hepatic cholesterol ( $\square$ ) and total lipid (圈) concentrations (mg/g) in rats fed for $28 \mathrm{~d}$ on diets containing cellulose, wheat bran, guar or sugar-beet fibre (SBF) $(100 \mathrm{~g} / \mathrm{kg})$. Values are means for ten rats with their standard errors indicated by vertical bars. Values significantly lower than either the cellulose or the bran control groups: ${ }^{*} P<0.05$. Value significantly lower than all other groups : $\uparrow P<0.05$.

Table 3. Hepatic and adipose tissue lipogenesis rates in rats fed on diets supplemented with wheat bran, cellulose, guar or sugar-beet fibre $(100 \mathrm{~g} / \mathrm{kg})^{*}$

(Mean values with their standard errors for ten rats per dietary group)

\begin{tabular}{|c|c|c|c|c|c|c|}
\hline \multirow{3}{*}{$\begin{array}{l}\text { Dietary } \\
\text { supplementation }\end{array}$} & \multirow{2}{*}{\multicolumn{2}{|c|}{$\begin{array}{c}\begin{array}{c}\text { Hepatic lipogenesis } \\
\text { (nmol glucose }\end{array} \\
\text { incorporated/g per h) }\end{array}$}} & \multicolumn{4}{|c|}{$\begin{array}{l}\text { Adipose tissue lipogenesis } \\
\text { (nmol acetate incorporated } / \mathrm{g} \text { per } \mathrm{h} \text { ) }\end{array}$} \\
\hline & & & \multicolumn{2}{|c|}{ Basal } & \multicolumn{2}{|c|}{$\begin{array}{l}\text { Insulin-stimulated } \\
\quad(2 \mathrm{nM} \text { insulin) }\end{array}$} \\
\hline & Mean & SEM & Mean & SEM & Mean & SEM \\
\hline Cellulose & $44 \cdot 6$ & $13 \cdot 6$ & 150 & 50 & 265 & 70 \\
\hline Bran & 38.6 & 6.4 & 220 & 55 & 335 & 105 \\
\hline Guar & $28 \cdot 0$ & $2 \cdot 2$ & 315 & 70 & 490 & 105 \\
\hline Sugar-beet fibre & $30 \cdot 0$ & $5 \cdot 2$ & 185 & 55 & 290 & 90 \\
\hline
\end{tabular}

* For details of diets and procedures, see Table 1 and pp. 386-388.

were higher in the SBF-fed group compared with the bran- and cellulose-fed groups, but the differences failed to reach statistical significance $(P<0 \cdot 1)$.

Faecal and circulating bile acid concentrations are shown in Fig. 4. Circulating bile acids were significantly lower in the guar- and SBF-fed groups compared with the bran- and cellulose-fed groups $(P<0.05)$. Faecal bile acid concentrations, expressed either as $\mu \mathrm{mol} / \mathrm{g}$ dry weight or as total daily output, were higher in the guar-fed group compared with the bran- and cellulose-fed groups $(P<0 \cdot 05)$. There was a trend towards higher faecal bile acid outputs in the SBF-fed group compared with bran and cellulose but the differences failed to reach statistical significance $(P<0 \cdot 1)$. Total daily faecal excretion, expressed as dry weight, was not affected by the dietary treatments. 


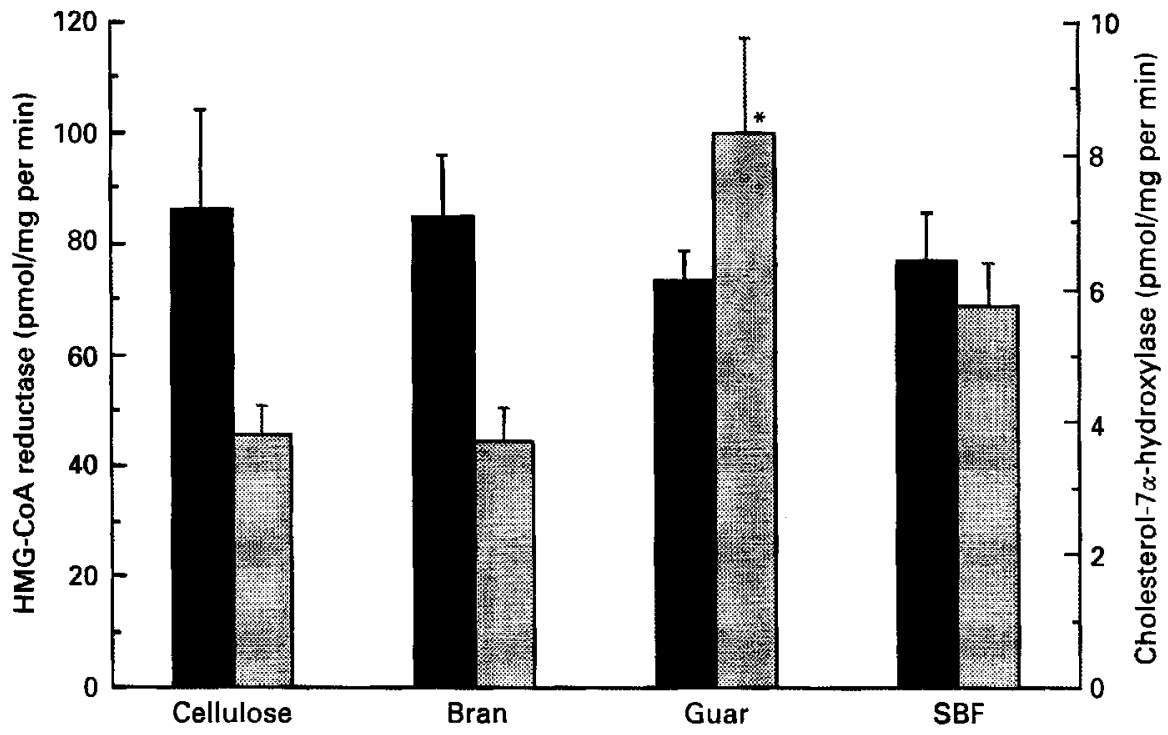

Fig. 3. Hepatic 3-hydroxy-3-methylglutaryl-CoA reductase (EC 1.1.1.88; $)$ ) and cholesterol-7 $\alpha$-hydroxylase (EC 1.14.13.17; 䉂) activities (pmol/mg per min) in rats fed for $28 \mathrm{~d}$ on diets containing cellulose, wheat bran, guar or sugar-beet fibre $(\mathrm{SBF})(100 \mathrm{~g} / \mathrm{kg})$. Values are means for ten rats with their standard errors indicated by vertical bars. Values significantly higher than either the cellulose or the bran control groups: ${ }^{*} P<0 \cdot 05$.

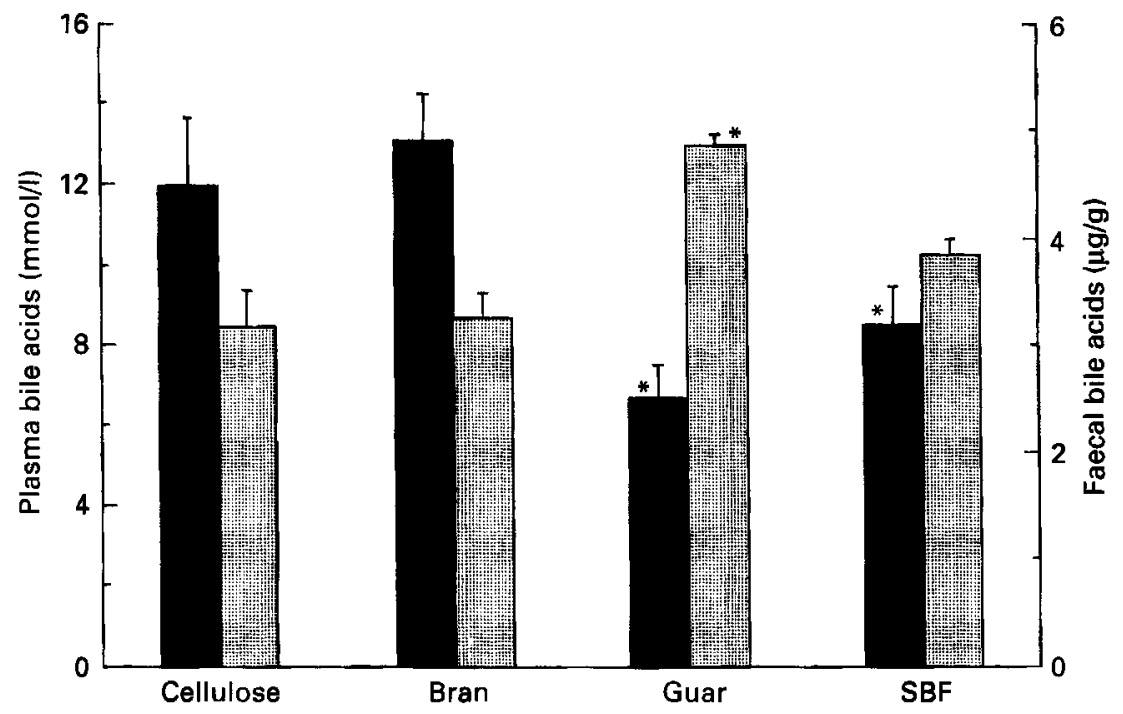

Fig. 4. Plasma ( $\mathrm{C}$ ) and faecal (图) bile acid concentrations (mmol/1 and $\mu \mathrm{g} / \mathrm{g}$ respectively) in rats fed for $28 \mathrm{~d}$ on diets containing cellulose, wheat bran, guar or sugar-beet fibre (SBF) $(100 \mathrm{~g} / \mathrm{kg})$. Values are means for ten rats with their standard errors indicated by vertical bars. Values significantly different from either the cellulose or the bran control groups: $* P<0-05$.

\section{DISCUSSION}

In the present study, inclusion of either guar or SBF into the diet of rats was observed to reduce both hepatic and circulating cholesterol levels compared with the control groups whose diets contained either cellulose or wheat bran. This is in broad agreement with 
previous human and animal studies (Jenkins et al. 1975; Johnson et al. 1990; Ide et al. 1991; Lampe et al. 1991; Tredger et al. 1991). Serum triacylglycerol levels were also markedly lowered in both guar- and SBF-fed animals. These observations are also in agreement with previous work (Vahouny et al. 1980; Hagander et al. 1989; Travis et al. 1990). Circulating triacylglycerol measurements were taken when animals were in the fed state, and are consistent with postprandial levels found in human subjects following guarand SBF-supplemented meals (Morgan et al. 1993).

The rat has limitations as a model for human cholesterol metabolism because of interspecies differences; in rats, circulating levels of cholesterol are generally lower than in humans, are not as responsive to dietary fat manipulation and are transported mainly in the HDL fraction. The gall bladder is also absent in the rat. However, the hepatic enzyme and metabolite measurements made in the present study precluded the use of human subjects. The hamster has recently emerged as a useful model of human lipoprotein metabolism as it carries a significant proportion of cholesterol in the low-densitylipoprotein (LDL) fraction and hepatic cholesterol synthesis rates are equivalent to those found in humans (Ohtani et al. 1990). Hamsters could not, however, be used in the present study because they possess a pre-gastric pouch which is a site of active fermentation, and there is evidence that guar gum can be fermented in this (Gallaher et al. 1993).

Faecal bile acid excretion was significantly higher and circulating bile acid levels were lowered in the guar-fed animals compared with the cellulose and bran control groups. This observation is consistent with previous human studies (Jenkins et al. 1976; Tredger et al. 1991) and supports the hypothesis that guar exerts its hypocholesterolaemic effect by altering the intestinal excretion of sterols. Indeed, the sequestration of intestinal bile acids by NSP and subsequent interruption of the enterohepatic bile acid circulation has been proposed by several workers as a mechanism where NSP exerts its hypocholesterolaemic effect (Bosaeus et al. 1986; Gallaher \& Schneeman, 1986; Floren \& Nilsson, 1987).

There was a trend towards increased faecal bile acid excretion in rats fed on the SBFsupplemented diet compared with those fed on the wheat bran or cellulose diets, although this failed to reach statistical significance. Power considerations dictate that animal group sizes of approximately fifty would be necessary to demonstrate a significant difference between groups with any confidence, because of the relatively small differences in group means (Gore \& Altman, 1982). We have previously demonstrated that the in vitro binding of SBF or wheat bran to glycocholic acid is very low compared with that of guar and have failed to show any acute postprandial effects of SBF or bran on the enterohepatic bile acid circulation (Morgan et al. 1993). Gallaher et al. (1992) have demonstrated raised faecal bile acid excretion in SBF-supplemented rats compared with animals on a fibre-free diet, but failed to show differences between animals fed on SBF-supplemented diets and those fed on barley bran supplements. In contrast, Lampe et al. (1991) found decreased faecal bile acid excretion in human volunteers given SBF or wheat bran compared with a fibre-free diet. These authors found that there was no correlation between faecal bile acid excretion and the hypocholesterolaemic effect of the NSP source when comparing SBF, wheat bran and mixed vegetables as the NSP source. A recent study in rats (Nishmura et al. 1993) has demonstrated that the hypocholesterolaemic effect of beet fibre does not depend on increased bile acid secretion, but that an intact caecum and colon is necessary for the fibre to be effective. These findings demonstrate that caution must be exercised in extrapolating the results of animal studies to the human situation, but it appears that increased bile acid excretion is unlikely to be a major mechanism whereby SBF exerts its hypocholesterolaemic effects.

Circulating bile acid levels were lowered in both guar- and SBF-fed animals relative to the control groups. We have previously found lowered fasting plasma bile acid levels in 
human subjects undergoing chronic dietary supplementation with either guar or SBF (Tredger et al. 1991) and lower postprandial bile acid levels in subjects given an acute test meal supplemented with guar, but not SBF (Morgan et al. 1993). The lower plasma bile acids in the guar-fed animals can be explained by the ability of guar to bind intestinal bile acids and increase their faecal excretion. The mechanism whereby SBF lowers circulating bile acids in the present study is less clear. Whilst increased faecal excretion of bile acids may play a small part, as evidenced by increased mean levels of faecal bile acid excretion in the SBF-fed animals, other factors must also be responsible. It is possible that SBF affects postprandial lipid absorption in rats, as evidenced by the lowered circulating triacylglycerol levels that accompanied the lowered plasma bile acids. Our inability to detect any changes in the rates of hepatic or adipose tissue lipogenesis in the present study which could account for the differences in circulating triacylglycerol levels observed between the groups reinforces this hypothesis. This mechanism could equally be partially responsible for the lowered plasma bile acids observed in the guar-fed animals.

Analysis of the rate-limiting enzyme of hepatic bile acid synthesis, cholesterol-7 $\alpha$ hydroxylase, demonstrated a raised activity in guar-fed animals and a trend towards higher activities in the SBF-fed group. This supports the view that an increase in the catabolism of hepatic cholesterol to bile acids is a factor in reducing plasma cholesterol in guar-fed rats and it may also play some role in the lowering of hepatic cholesterol levels in the SBF-fed rats. Changes in cholesterol-7 $\alpha$-hydroxylase activity generally occur in parallel with changes in the faecal excretion of bile acids as was observed in the guar-fed animals and by the trends observed in the SBF-fed group. Under most physiological and experimental conditions the activity of HMG-CoA reductase, the rate limiting enzyme in the cholesterol biosynthetic pathway, changes in the same direction as cholesterol- $7 \alpha$-hydroxylase (Pandak et al. 1990). In the present study HMG-CoA reductase levels were unaffected by the dietary treatments in spite of differences in cholesterol- $7 \alpha$-hydroxylase activities. These findings are consistent with the lowered hepatic cholesterol levels observed in the guar- and SBF-fed groups as increased hepatic cholesterol catabolism via bile acid synthesis has not been compensated by an increase in hepatic cholesterol synthesis. NSP can be fermented in the large intestine to produce volatile fatty acids (VFA), and it has been hypothesized that the hypocholesterolaemic effect of NSP may be due to the inhibitory effect of these VFA on HMG-CoA reductase activity (Chen et al. 1984). The present study does not support this hypothesis for the NSP tested, as HMG-CoA reductase activity was unaffected by the dietary treatments. However, the VFA produced from the high level of NSP consumed throughout the dietary supplementation period could have exerted an inhibitory effect across all dietary groups and led to decreased hepatic cholesterol levels in the guar- and, to an extent, the SBF-fed animals, where hepatic cholesterol output was increased.

The present study has supported the hypothesis that guar exerts its hypocholesterolaemic effect via intraluminal bile acid binding with consequent interruption of the enterohepatic bile acid circulation and loss of cholesterol from increased faecal bile acid excretion. Interference with the intestinal uptake of lipid by guar as a result of bile acid sequestration may increase guar's hypocholesterolaemic effect. Studies with guar in human subjects indicate that these mechanisms are likely to apply to the human situation (Morgan et al. 1993). The mechanisms whereby SBF exerts its hypocholesterolaemic effects are less clear. In the SBF-fed animals their hypocholesterolaemia was accompanied by a reduction in hepatic cholesterol and in circulating triacylglycerol and bile acids, pointing to a mechanism involving the disruption of the enterohepatic bile acid circulation possibly via changes in absorption patterns of triacylglycerol and its subsequent handling by circulating lipoproteins. It seems likely that the cholesterol-lowering action of SBF is effected by a number of factors rather than a single mechanism. These factors could apply to the ability 
of SBF to lower cholesterol in the human situation, although differences in customary levels of dietary fat intake and in lipoprotein metabolism between humans and rodents would need to be taken into account before extrapolating between species.

We are grateful to British Sugar plc for their financial support and the provision of sugarbeet fibre and to Rybar Laboratories, who supplied the guar gum.

\section{REFERENCES}

Betteridge, D. J. (1989). Lipids, diabetes and vascular disease: the time to act. Diabetic Medicine 6, 195-218.

Bligh, E. G. \& Dyer, W. J. (1959). A rapid method of total lipid extraction and purification. Canadian Journal of Biochemistry and Physiology 37, 911-917.

Bosaeus, I., Carlsson, N. G., Sandberg, A. S. \& Andersson, H. (1986). Effect of wheat bran and pectin on bile acid and cholesterol excretion in ileostomy patients. Human Nutrition: Clinical Nutrition 40, 429-440.

Bradford, M. M. (1976). A rapid and sensitive method for the quantitation of microgram quantities of protein utilizing the principle of protein dye binding. Analytical Biochemistry 72, 248-254.

Chen, W. J., Anderson, J. W. \& Jennings, D. (1984). Propionate may mediate the hypocholesterolemic effects of certain soluble plant fibers in cholesterol-fed rats. Proceedings of the Society for Experimental Biology and Medicine 175, 215-218.

Dils, R. R. \& Forsyth, I. A. (1981). Preparation and culture of mammary gland explants. Methods in Enzymology 72, 724-742.

Florén, C. H. \& Nilsson, A. (1987). Binding of bile salts to fibre-enriched wheat fibre. Scandinavian Journal of Gastroenterology 129 (Suppl.), 192-199.

Folch, J., Lees, M. \& Sloane Stanley, G. H. (1957). A simple method for the isolation and purification of total lipids from animal tissues. Journal of Biological Chemistry 226, 497-499.

Gallaher, D., Hassel, C. A., Kyung, J. L. \& Gallaher, C. (1993). Viscosity and fermentability as attributes of dietary fiber responsible for the hypocholesterolemic effect in hamsters. Journal of Nutrition 123, $244-252$.

Gallaher, D., Locket, P. L. \& Gallaher, C. M. (1992). Bile acid metabolism in rats fed two levels of corn oil and brans of oat, rye and barley and sugar beet fiber. Journal of Nutrition 122, 473-481.

Gallaher, D. \& Schneeman, O. (1986). Intestinal interaction of bile acids, phospholipids, dietary fibers and cholestyramine. American Journal of Physiology 250, G420-G426.

Gore, S. M. \& Altman, D. G. (1982). How large a sample? In Statistics in Practice, pp. 6-9. Torquay: Devonshire Press.

Hagander, B., Asp, N. G., Efendic, S., Nilsson-Ehle, P. \& Schersten, B. (1988). Dietary fiber decreases fasting blood glucose levels and plasma LDL concentration in non-insulin-dependent diabetes mellitus patients. American Journal of Clinical Nutrition 47, 852-858.

Hagander, B., Asp, N. G., Ekman, R., Nilsson-Ehle, P. \& Schersten, B. (1989). Dietary fibre enrichment, blood pressure, lipoprotein profile and gut hormones in NIDDM patients. European Journal of Clinical Investigation 43, 35-43.

Hansen, W. E., Maurer, H., Vollmar, J. \& Brauning, C. W. (1983). Guar gum and bile: effects on postprandial gallbladder contraction and on serum bile acids in man. Hepatogastroenterology 30, 131-133.

Ide, T., Moriuchi, H. \& Nihimato, K. (1991). Hypolipemic effects of guar gum and its enzyme hydrolysate in rats fed highly saturated fat diets. Annals of Nutrition and Metabolism 35, 34-44.

Jenkins, D. J. A., Leeds, A. R., Gassull, M. A., Houston, H., Goff, D. V. \& Hill, M. J. (1976). The cholesterol lowering properties of guar and pectin. Clinical Science and Molecular Medicine 51, 8P-9P.

Jenkins, D. J. A., Leeds, A. R., Newton, C. \& Cummings, J. H. (1975). The effect of pectin, guar gum and wheat fibre on serum cholesterol. Lancet ii, 1116-1119.

Johnson, I. T., Livesey, G., Gee, J. M., Brown, J. C. \& Worthy, G. M. (1990). The biological effects and digestible energy value of a sugar-beet fibre preparation in the rat. British Journal of Nutrition 64, 187-199.

Kritchevsky, D., Vahouny, G. V. \& Story, J. A. (1986). Dietary fibre and lipid metabolism. In Proceedings of the XIII International Congress of Nutrition, 1985, pp. 175-181 [T. G. Taylor and W. K. Jenkins, editors]. London: John Libbey.

Lampe, J. W., Slavin, J. L., Baglien, K. S., Thompson, W. O., Duane, W. C. \& Zavoral, J. H. (1991). Serum lipid and fecal bile acid changes with cereal, vegetable and sugar-beet fiber feeding. American Journal of Clinical Nutrition 53, 1235-1241.

McGrath, S. A. H. \& Rao, G. A. (1977). Stimulation of hepatic lipogenesis by eicosa-5,8,11,14-tetraenoic acid in mice fed a high linoleate diet. Lipids 2, $446-449$.

Morgan, L. M., Tredger, J. A., Shavila, Y., Travis, J. S. \& Wright, J. (1993). The effect of non-starch polysaccharide supplementation on circulating bile acids, hormone and metabolite levels following a fat meal in human subjects. British Journal of Nutrition 70, 491-501.

Nimmannit, S. \& Porter, J. W. (1980). Cholesterol $7 \alpha$-hydroxylase: solubilization and determination of enzyme activity. Archives of Biochemistry and Biophysics 201, 533-543. 
Nishmura, N., Nishikawa, H. \& Kirigama, S. (1993). Ileorectostomy or cecectomy but not colectomy abolishes the plasma cholesterol-lowering effect of dietary beet fiber in rats. Journal of Nutrition 123, 1260-1269.

Oben, J., Morgan, L., Fletcher, J. \& Marks, V. (1991). Effect of the entero-pancreatic hormones, gastric inhibitory polypeptide and glucagon-like polypeptide-1(7-36) amide, on fatty acid synthesis in explants of rat adipose tissue. Journal of Endocrinology 130, 267-272.

Ohtani, H., Hayashi, K., Hirata, Y., Dojo, S., Nakashima, K., Nishio, E., Kurushima, H., Saeki, M. \& Kajiyama, G. (1990). Effects of dietary cholesterol and fatty acids on plasma cholesterol level and hepatic lipoprotein metabolism. Journal of Lipid Research 31, 1413-1422.

Pandak, W. M., Heuman, D. M., Hylemon, P. B. \& Vlahcevic, Z. R. (1990). Regulation of bile acid synthesis. IV. Interrelationship between cholesterol and bile acid biosynthesis pathways. Journal of Lipid Research 31, 79-90.

Rudel, L. L. \& Morris, M. D. (1973). Determination of cholesterol using $O$-phthaldehyde. Journal of Lipid Research 14, 364-367.

Shapiro, D. J., Nordstrom, J. L., Mitschelen, J. J., Rodwell, V. W. \& Schimke, R. T. (1974). Micro assay for 3hydroxy-3-methylglutaryl-CoA reductase in rat liver and in $\mathbf{L}$ cell fibroblasts. Biochimica et Biophysica Acta 370, 369-377.

Starkey, B. J. \& Marks, V. (1982). Determination of total bile acids in serum - a comparison of radioimmunoassay with an enzymatic-fluorimetric method. Clinica Chimica Acta 119, 165-177.

Travis, J. S., Morgan, L. M., Tredger, J. A. \& Marks, V. (1990). Effects of sugar beet fibre on blood glucose, serum lipids and apolipoproteins in non-insulin dependent diabetes mellitus. In Dietary Fibre: Chemical and Biological Aspects, pp. 368-372 [D. A. T. Southgate, K. Waldron, I. T. Johnson and G. R. Fenwick, editors]. Cambridge: Royal Society of Chemistry.

Tredger, J. A., Morgan, L. M., Travis, J. \& Marks, V. (1991). The effects of guar gum, sugar beet fibre and wheat bran supplementation on serum lipoprotein levels in normocholesterolaemic volunteers. Journal of Human Nutrition and Dietetics 4, 375-384.

Tuomilehto, J., Happonen, P., La Ville, A. E., Shaikh, M. \& Lewis, B. (1990). Metabolic studies on the hypolipidemic effect of guar gum. Atherosclerosis 81, 145-150.

Vahouny, G. V., Roy, T., Gallo, L. L., Story, J. A., Kritchevsky, D. \& Cassidy, M. (1980). Dietary fibers III: effects of chronic intake on cholesterol absorption and metabolism in the rat. American Journal of Clinical Nutrition 33, 2182-2191.

Van Cantfort, J., Renson, J. \& Gielen, J. (1975). Rat liver cholesterol-7 $\alpha$-hydroxylase. European Journal of Biochemistry 55, 23-31. 